\title{
Conventional treatments for ankylosing spondylitis
}

\section{Dougados, B Dijkmans, M Khan, W Maksymowych, Si van der Linden, J Brandt}

See end of article for authors' affiliations

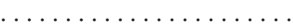

Correspondence to: Dr M Dougados, Clinique de Rhumatologie, Hôpital Cochin, 27 rue du Faubourg Saint Jacques, F-75014 Paris, France; maxime.dougados@ cch.ap-hop-paris.fr

\begin{abstract}
Management of ankylosing spondylitis (AS) is challenged by the progressive nature of the disease. To date, no intervention is available that alters the underlying mechanism of inflammation in AS. Currently available conventional treatments are palliative at best, and often fail to control symptoms in the long term. Current drug treatment may perhaps induce a spurious state of "disease remission," which is merely a low level of disease activity. Non-steroidal anti-inflammatory drugs are first line treatment, but over time, the disease often becomes refractory to these agents. Disease modifying antirheumatic drugs are second line treatment and may offer some clinical benefit. However, conclusive evidence of the efficacy of these drugs from large placebo controlled trials is lacking. Additionally, these drugs can cause treatment-limiting adverse effects. Intra-articular corticosteroid injection guided by arthrography, computed tomography, or magnetic resonance imaging is an effective means of reducing inflammatory back pain, but controlled studies are lacking. A controlled study has confirmed moderate but significant efficacy of intravenous bisphosphonate (pamidronate) treatment in patients with AS; further evaluation of bisphosphonate treatment is warranted. Physical therapy and exercise are necessary adjuncts to pharmacotherapy; however, the paucity of controlled data makes it difficult to identify the best way to administer these interventions. Surgical intervention may be required to support severe structural damage. Thus, for patients with AS, the future of successful treatment lies in the development of pharmacological agents capable of both altering the disease course through intervention at sites of disease pathogenesis, and controlling symptoms.
\end{abstract}

\section{MEDICAL TREATMENT}

\section{Non-steroidal anti-inflammatory drugs}

Considered the cornerstone of pharmacological intervention for the spondyloarthropathies (SpAs), ${ }^{1}$ non-steroidal antiinflammatory drugs (NSAIDs) rapidly reduce the signs and symptoms of axial involvement in patients with SpAs. ${ }^{2}$ In patients with AS, numerous studies have demonstrated the ability of NSAIDs to provide rapid and dramatic relief of inflammatory back pain, ${ }^{13-8}$ such that NSAID response is now considered a helpful diagnostic feature of AS (discussed below). ${ }^{9}$ However, after the withdrawal of NSAID treatment, rebound symptoms of inflammation (joint pain, swelling, and stiffness) generally appear within a few days (five or six half lives of the drug). Furthermore, there is no evidence that NSAIDs alter the underlying pathogenetic mechanism of

inflammation in rheumatoid arthritis (RA) and other arthritides, so structural damage may continue to occur despite symptomatic improvement. ${ }^{10}$

Phenylbutazone, the first NSAID that became generally available, is considered the most effective, but its potential toxicity limits its use. ${ }^{2}$ Although the second generation NSAIDs are generally less toxic, their use is often limited by gastrointestinal adverse effects. These effects occur secondary to inhibition of cyclo-oxygenase 1 (COX-1), the constitutive cyclo-oxygenase enzyme believed to be responsible for the physiological production of cytoprotective prostaglandins in the gastric mucosa. ${ }^{10}$ About $10-60 \%$ of patients receiving these NSAIDs have minor gastrointestinal symptoms such as nausea, dyspepsia, epigastric pain, and diarrhoea. ${ }^{11}$ More serious gastrointestinal effects in the form of symptomatic gastrointestinal ulcers, and potentially life threatening ulcer related sequelae, such as upper gastrointestinal bleeding, perforation, and gastric outlet obstruction, occur in approximately $1-2 \%$ of patients using these NSAIDs for three months, and in $2-4 \%$ of patients using these NSAIDs for 12 months. ${ }^{12}$ Prospective controlled data from patients with RA indicate that older patients, those with previous peptic ulcer or gastrointestinal bleeding, or a history of cardiovascular disease have a 2- to 2.5-fold increase in risk of serious gastrointestinal complications (that is, bleeding, perforation, or obstruction). ${ }^{13}$

Abbreviations: AS, ankylosing spondylitis; 5-ASA, 5-acetylsalicylic acid; ASAS, Assessments in Ankylosing Spondylitis (Working Group); BASDAI, Bath AS Disease Activity Index; BASFI, Bath AS Functional Index; BASGI, Bath AS Global Index; BASMI, Bath AS Metrology Index; COX, cyclo-oxygenase; CRP, $C$ reactive protein; $C T$, computed tomography; DMARD, disease modifying antirheumatic drug; ESR, erythrocyte sedimentation rate; IV, intravenous; MES, mesalazine; MRI, magnetic resonance imaging; NSAID, non-steroidal anti-inflammatory drug; RA, rheumatoid arthritis; SP, sulfapyridine; SpA, spondyloarthropathy; SSZ, sulfasalazine; THA, total hip arthroplasty; VAS, visual analogue scale 
Comorbid medical diseases, the type of NSAID, the use of multiple NSAIDs, and the combined use of NSAIDs and corticosteroids are also risk factors. ${ }^{14}$

Compared with standard NSAIDs (including naproxen, diclofenac, ibuprofen, nabumetone), the newest generation of NSAIDs, the selective COX-2 inhibitors (for example, celecoxib, rofecoxib), are associated with a marked decrease in risk of the aforementioned serious gastrointestinal adverse effects. However, they are not significantly more efficacious. ${ }^{15}$ Large controlled trials of celecoxib $(n=7968$, $\mathrm{n}=1149)^{15}{ }^{16}$ and rofecoxib $(\mathrm{n}=775),{ }^{17}$ and a combined analysis of eight double blind trials of rofecoxib $(n=5435)^{18}$ in patients with RA or osteoarthritis, consistently demonstrated statistically significant reductions in the incidence of symptomatic or endoscopic gastroduodenal ulcers and ulcer complications (bleeding, perforation, and obstruction) in patients receiving these COX-2 inhibitors compared with those receiving standard NSAIDs. However, the rates of less serious, more common gastrointestinal symptoms (dyspepsia, abdominal, pain, nausea, flatulence, diarrhoea) were only marginally reduced; for example, across two studies of rofecoxib and celecoxib, dyspepsia or dyspeptic-like symptoms were reduced by only $1-2 \%$ in patients with RA or osteoarthritis. ${ }^{15}{ }^{18}$ A recent study determined that there was a higher risk of thrombotic cardiovascular events in patients treated with rofecoxib compared with naproxen. ${ }^{19}$ Further studies are needed to establish definitively the extent of risk, but caution is advisable in cases where coxibs are used for chronic treatment, particularly in patients with cardiovascular disease.

The reduced risk of serious gastrointestinal events with COX-2 inhibitors warrants their testing in AS. It should be noted, however, that most patients with AS fall into a fairly low risk group for serious gastrointestinal complications (men aged $<50$ years with no history of corticosteroid or NSAID use). None the less, in this patient subgroup the risk of a serious gastrointestinal event or major gastrointestinal bleed associated with COX-2 specific inhibitors is close to zero, ${ }^{15}{ }^{18}$ a risk reduction that should be considered as clinically relevant. However, from the perspective of overall gastrointestinal effect risk reduction and tolerance for these low risk patients, it is unlikely that COX-2 inhibitors provide substantial therapeutic advantage over standard NSAIDs in the short term. In this group, approximately 500 patients will need to be treated (number needed to treat) to avoid one serious gastrointestinal complication, relative to standard NSAID treatment. ${ }^{20}$ Furthermore, given the high cost of COX-2 inhibitors, their use by patients at low risk for ulcer complications is not likely to be cost effective. COX-2 inhibitors may be of benefit in patients intolerant of several non-selective NSAIDs, and in those at high risk for serious gastrointestinal complications (for example, patients with a history of ulcers or gastrointestinal bleeding). Another aspect to consider is that for patients with AS who undergo a long term daily intake of NSAIDs (that is, for several decades), NSAID gastrotoxicity may be a clinically relevant problem even in the low risk patient subgroup. COX-2 inhibitors may be of particular interest for such patients.

\section{NSAIDs as diagnostic tools}

The rapid acting and substantial symptomatic effect of NSAIDs, especially on axial involvement of AS, is used as a potential tool to diagnose the disorder. Substantial improvement of back pain within 48 hours of NSAID administration or rapid relapse of pain after discontinuation is item number 12 in the spondyloarthropathy diagnostic criteria proposed by Amor et al. ${ }^{21}$ In a large cross sectional study conducted in French hospitals in 1980, 69/741 (9\%) patients with back pain were diagnosed with AS. ${ }^{9}$ Fifty three of these 69 patients (77\%) with AS showed clear improvement of back pain after NSAID intake, compared with $15 \%$ of all other patients with back pain, for a sensitivity of $77 \%$ and a specificity of $85 \%$,
Box 1 ASAS Response and remission criteria

\section{ASAS response criteria}

Improvement of $\geqslant 20 \%$ and absolute improvement of $\geqslant 10$ on

a $0-100$ scale in $\geqslant 3$ of the following domains*:

- Patient global assessment

- Pain

- Function

- Inflammation

- Absence of deterioration lof $\geqslant 20 \%$ and absolute deterioration of $\geqslant 10$ on a $0-100$ scale) in the potential remaining domain.

ASAS remission criterio

A value $<20$ on a $0-100$ scale in each of the following four domains*:

- Patient global assessment

- Pain

- Function

- Inflammation.

*Definition of the domains: patient global assessment=VAS; (0-100); pain=VAS global, past two days (0-100); function=BASFI (0-100); inflammation, either by (first choice) the mean of the two morning stiffness related BASDAI VAS scores, or by (second choice) morning stiffness duration with a maximum of $120 \mathrm{~mm}$ (0-100 scale).

ASAS, Assessments in Ankylosing Spondylitis; BASDAI, Bath Ankylosing Spondylitis Disease Activity Index; BASFI, Bath Ankylosing Spondylitis Functional Index; VAS, visual analogue scale.

respectively. These findings showed that the positive predictive value for AS was 34\%. Inversely, if a patient's back pain did not respond to NSAID administration, the possibility of AS was $3 \%$, indicating a negative predictive value of $97 \%$.

\section{Evaluating NSAID efficacy in AS}

The definition of outcome parameters by the Assessments in Ankylosing Spondylitis (ASAS) Working Group has aided progress in determining the efficacy of pharmacological agents for the treatment of $\mathrm{AS}^{.22-24}$ (The assessment of outcome in AS is reviewed by van der Heijde et al in "Treatment trials in ankylosing spondylitis: current and future considerations" within this supplement (p iii24).)

In brief, the ASAS group established a core set of five domains relevant to assessment of AS symptomatic outcome (physical function, pain, spinal mobility, spinal stiffness/ inflammation, and patient's global assessment) and selected instruments for assessment of each domain. ${ }^{22}{ }^{23}$ The ASAS group recently published criteria for the assessment of short term improvement with symptom modifying antirheumatic drugs using outcome data from five short term, randomised, controlled trials of NSAIDs (piroxicam, ximoprofen, and ketoprofen) ${ }^{24}$ The criteria are composed of a composite index of four domains: patient global assessment, pain, functional impairment, and inflammation (defined by duration and intensity of morning stiffness). The ASAS group chose the Bath Ankylosing Spondylitis Functional Index (BASFI) for the evaluation of functional impairment as a response/ remission criterion because of its simplicity of use (10 questions). Additionally, because for functional impairment there is very little placebo effect in placebo controlled evaluations of treatments for AS, short term treatment effect is easy to detect. Response and remission criteria for improvement in AS developed by the ASAS group (box 1$)^{24}$ facilitate the interpretation of short term clinical trial results. Of note is that the remission criteria actually represent a state of low disease activity. The working group also set expected levels of response for patients who are naive to treatment at $25 \%$ for placebo and $50 \%$ for treatment. However, in light of the fact that the disease remains active regardless of any current intervention, 
BASFI

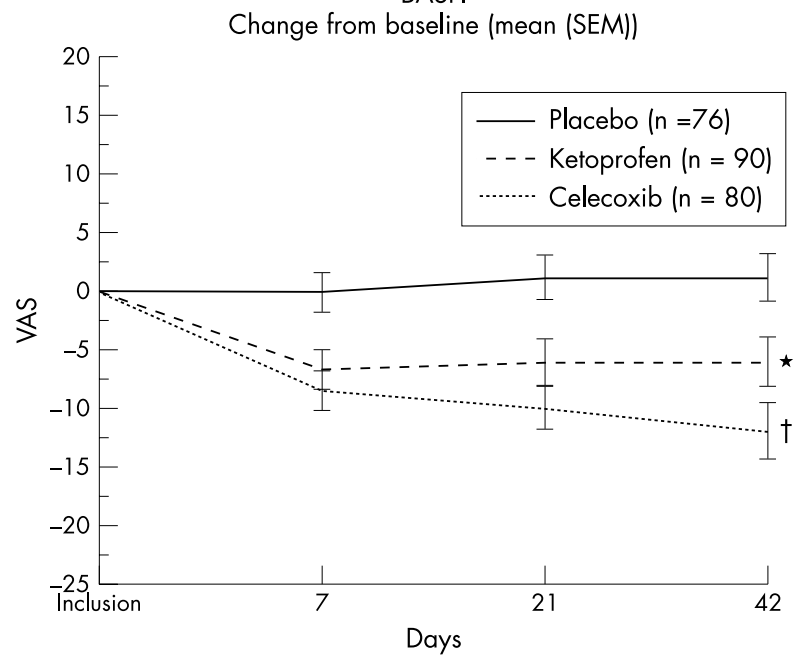

Figure 1 Short term symptomatic efficacy of celecoxib and ketoprofen in treating ankylosing spondylitis ${ }^{4} ; p=0.0008$ (treatment), ${ }^{*} p<0.05 v$ placebo, $\uparrow p<0.001 v$ placebo. Adapted and reprinted, with permission from the authors and Wiley-Liss, Inc, a subsidiary of John Wiley and Sons, Inc, from reference 4. Copyright (C) 2001 Wiley-Liss.

whether clinicians should be satisfied with a $50 \%$ response rate is an issue for debate.

Because of the lack of placebo effect on function in AS, together with the availability of validated clinical criteria for activity of $\mathrm{AS},{ }^{2}$ the diagnostic value of a response to NSAID treatment, ${ }^{9}$ and the high probability of absent concomitant treatment (because AS occurs in younger patients), AS has been suggested as a relevant human model for evaluation of NSAIDs. Although RA is the most common human model for evaluating new drugs for chronic inflammatory rheumatic diseases, it has been proposed that AS might be a more sensitive model. ${ }^{5}$ The general lack of concomitant treatment in the relatively young AS population may explain the greater sensitivity of this model.

The appropriateness of AS as a human model for assessment of new NSAIDs (and other drugs) is illustrated by the outcomes of a recent six week, randomised, double blind, placebo controlled study of 246 patients with AS. Celecoxib, a COX-2-specific inhibitor, at a low dose of $200 \mathrm{mg} /$ day, was compared with ketoprofen (200 mg/day). ${ }^{4}$ Patients had AS according to the modified New York criteria without peripheral synovitis and active disease with pain $\geqslant 40 \mathrm{~mm}$ on a $100 \mathrm{~mm}$ visual analogue scale (VAS) and an increase in pain of at least $30 \%$ after NSAID drug withdrawal. Primary outcome measures were change in pain intensity (VAS) and change in functional impairment, measured by the BASFI. A significant reduction (that is, improvement) in mean functional impairment (BASFI) was observed in patients treated with both ketoprofen $(-6)$ and celecoxib $(-12) \quad(p=0.05$, $\mathrm{p}=0.001$, respectively) (fig 1 ), but no placebo effect was seen.

\section{Determining optimal NSAID dose}

Detecting a treatment effect between two doses of the same NSAID or between different NSAIDs is much more difficult than detecting a treatment effect relative to placebo. Also, whereas a one week trial is sufficient to detect a treatment effect, short term trials (for example, six weeks) do not appear to be adequate for determining NSAID dosage in AS. ${ }^{25} \mathrm{~A}$ double blind, placebo controlled, dose ranging study of ximoprofen $(5,10,20,30 \mathrm{mg}$ daily) in 285 patients with AS found a two week trial period to be insufficient to identify the optimal NSAID dose. ${ }^{5}$ At the end of the first week, a stepwise increase was observed in a percentage of treatment responders (response was defined as $\geqslant 50 \%$ decrease in pain (VAS)) up to the $20 \mathrm{mg}$ dose, followed by a slight reduction at $30 \mathrm{mg}$ ( fig 2). This pattern of response was no longer evident at the end of the second week. At that point (end of the study), no significant difference was seen between the different ximoprofen dose subgroups; response rates were $54 \%, 41 \%$, and $53 \%$ in the 5, 10, and 20 mg groups, respectively.

Results of a prospective, multicentre, double blind, placebo controlled trial of NSAIDs (meloxicam 15 or $22.5 \mathrm{mg}$ daily, piroxicam $20 \mathrm{mg}$ daily) of six weeks' duration with a 12 month double blind extension phase suggest that long term evaluation (that is, at least 12 months) is required to detect NSAID dose differences in patients with AS. ${ }^{25}$ In that study treatment response was defined as $\geqslant 50 \%$ reduction in the relevant efficacy variable: patient's global assessment of disease activity using a VAS, pain over the previous two days using a VAS, and functional disability; and no requirement for drug discontinuation because of lack of efficacy. Assessment of efficacy at six weeks and at 52 weeks using the percentage of responders as the end point detected no significant difference between the three active NSAID groups. The percentages of responders for patient's global assessment were 37\%,50\%, and $43 \%$ for the piroxicam $20 \mathrm{mg}$, meloxicam $15 \mathrm{mg}$, and meloxicam $22.5 \mathrm{mg}$ groups, respectively. However, life table analysis of the patients discontinuing the study drug for any reason over a 52 week period permitted the detection of a significantly better treatment response in patients receiving $22.5 \mathrm{mg}$ of meloxicam than in those treated with $15 \mathrm{mg}$ of meloxicam $(p<0.05) .{ }^{25}$ The $22.5 \mathrm{mg}$ group had a $37 \%$ rate of withdrawals for any reason, compared with $53 \%$ for the $15 \mathrm{mg}$ group and $74 \%$ for the placebo group (the piroxicam group had a 53\% withdrawal rate). The high placebo withdrawal rate
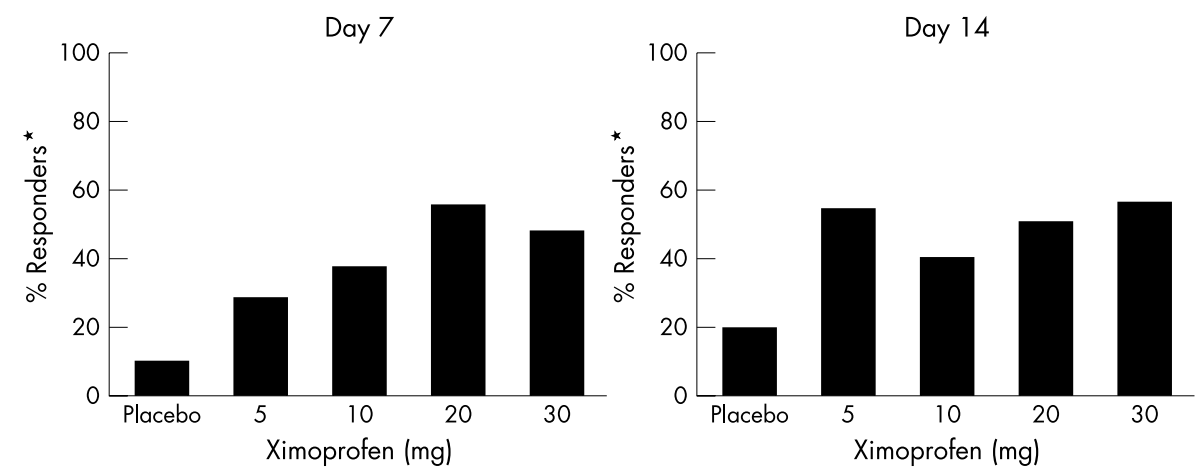

^ Responders: $\geq 50 \%$ improvement in pain VAS

Figure 2. Short term symptomatic efficacy of ximoprofen in treating ankylosing spondylitis in a dose ranging study. ${ }^{5}$ Adapted and reprinted, with permission from the authors and the Scandinavian Journal of Rheumatology, from reference 5. Copyright () 1994 Taylor and Francis. 


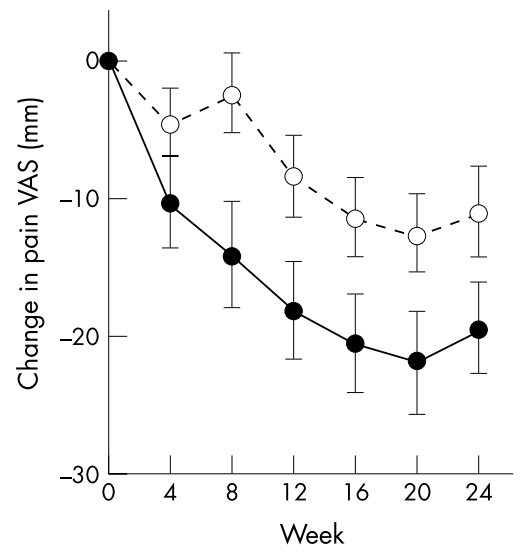

Ankylosing spondylitis

Placebo $=59$ patients

Sulfasalazine $=50$ patients

$\mathrm{p}=0.11$

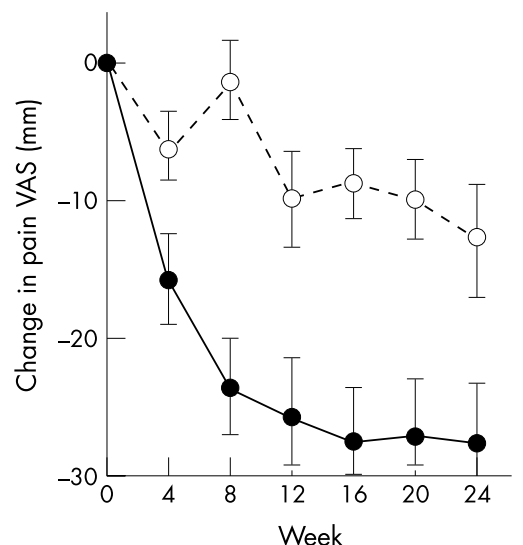

Week

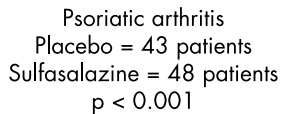

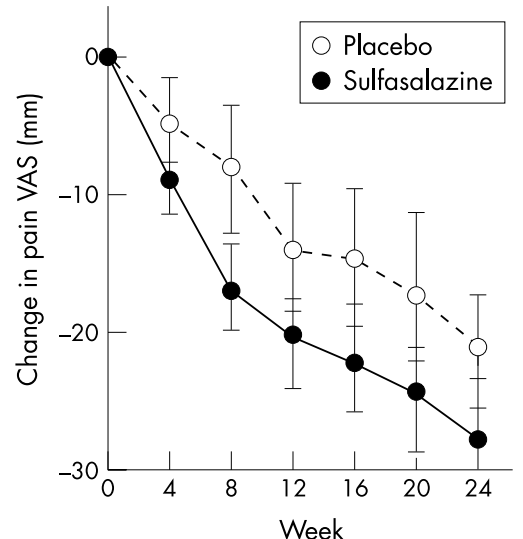

Reactive arthritis

Placebo $=35$ patients

Sulfasalazine $=28$ patients

$p=0.44$

Figure 3 Effect of sulfasalazine on pain (measured on a VAS) over time among patients who completed six months of the study, by disease subgroup (ankylosing spondylitis, psoriatic arthritis, and reactive arthritis). Statistical analysis was performed using repeated measures analysis of variance. ${ }^{28}$ Adapted and reprinted, with permission from the authors and Wiley-Liss, Inc, a subsidiary of John Wiley and Sons, Inc, from reference 28. Copyright @ 1995 Wiley-Liss.

suggests that a longer trial also allows for better evaluation of tolerability of candidate drugs.

\section{Continuing treatment with NSAIDs}

The decision to start NSAID treatment in patients with painful AS is simple. However, after the patient improves with initial NSAID treatment, the direction of long term treatment becomes much more difficult to determine. To date, no consensus has been reached on whether NSAIDs should be given continuously or discontinued after initial control and re-administered only during disease flare ups. Although anecdotal evidence suggests that regular NSAID intake may facilitate continuing physical therapy and may even have a positive structural effect on joints, many doctors favour limited use of NSAIDs to reduce the risk of serious gastrointestinal complications.

The placebo controlled trial of celecoxib and ketoprofen described previously ${ }^{1}$ also had a two year, open label, follow up extension phase after the six week, double blind phase (Dougados $M$, personal communication). At the end of the six week study phase, patients were randomised to two groups: one group was to continue celecoxib $200 \mathrm{mg} /$ day and to increase the dose to $400 \mathrm{mg} /$ day in the event of disease flare, and the other group was to discontinue celecoxib as soon as symptoms receded, and to restart celecoxib in the event of disease flare. The two year data, which are pending, will include quality of life, functional impairment, pain, and mean daily NSAID dose, as well as the structural effect of NSAIDs.

When an NSAID loses efficacy in a patient with AS, several issues need to be considered. Is the patient receiving the optimal dosage? How many different doses should be tried? Has the drug been given enough time to take effect? What other NSAIDs should be evaluated? Once it is determined that the patient's disease has become refractory to optimal NSAID treatment, other treatment options need to be explored. The best approach to managing NSAID refractivity, however, is also the subject of some debate. At present, the standard practice is to give second line drugs.

\section{Disease modifying antirheumatic drugs (DMARDs)}

Second line drugs should be considered not only when a patient becomes refractory to NSAIDs but also when a patient has persistent articular involvement, is in the advanced, severe stages of the disease, or has serious side effects from NSAIDs. DMARDs comprise one group of therapeutic agents that are candidates for second line treatment of AS, although their efficacy in AS has not yet been established. Many of these compounds have been thoroughly tested and proved beneficial in RA, but testing and use of DMARDs in AS has not kept pace. Furthermore, the evaluation of published data on the effect of DMARDs (antimalarial drugs, gold, azathioprine, methotrexate, and sulfasalazine) in AS is difficult because although most of the published studies indicate that the enrolled study patients fulfilled the diagnostic criteria for AS, details of their clinical presentation, in particular, the distinction between axial involvement and peripheral articular involvement, are not provided.

\section{Sulfasalazine}

Sulfasalazine (SSZ) is the best studied DMARD used as a second line treatment in the SpAs. ${ }^{26}$ At least 10 double blind trials have been reported. However, its efficacy remains unclear. A meta-analysis of five randomised controlled studies conducted in 1990 concluded that SSZ provided some potential benefit for clinical symptoms of AS. ${ }^{27}$ In contrast, results of two subsequent major double blind, placebo controlled evaluations of SSZ in AS failed to demonstrate substantial therapeutic efficacy. ${ }^{28} 29$

The first evaluation was a multicentre six month trial involving a total of 351 patients with SpA, divided into three disease subgroups: AS $(n=134)$, psoriatic arthritis $(n=136)$, or reactive arthritis $(\mathrm{n}=81) .^{28} \mathrm{SSZ}$ was given at a maximum dose of $3 \mathrm{~g} /$ day. The primary outcome measures included pain (evaluated using VAS), degree of inflammation assessed primarily by duration of early morning stiffness, functional impairment assessed by a functional index, and the doctor's and patient's overall assessments. Intention to treat analysis showed a significant improvement with SSZ in only one primary outcome variable: patient's overall assessment $(\mathrm{p}=0.007)$. SSZ had no significant effect on pain, morning stiffness, or doctor's global assessment. A significant decrease $(p<0.001)$ was also seen in erythrocyte sedimentation rate (ESR) (secondary efficacy variable). Analysis of data from patients completing the study showed significant improvement in pain $(p=0.03)$, and in patient's $(p=0.006)$ and doctor's $(p=0.031)$ overall assessment. This analysis failed to show a significant effect of SSZ on morning stiffness (inflammation). Analysis of changes by treatment group and disease subgroup failed to demonstrate significant efficacy of SSZ in improving pain in patients with AS (fig 3); efficacy was shown 
only in patients with psoriatic arthritis $(\mathrm{p}<0.001)$. Adverse events led to premature discontinuation of SSZ in 28/179 (16\%) patients compared with 9/172 (5\%) placebo recipients.

The second evaluation was a multicentre 36 week trial involving 264 patients with evidence of active AS refractory to NSAIDs, defined as morning stiffness of $\geqslant 45$ minutes' duration, inflammatory back pain, and patient and doctor global assessments of moderate or higher disease activity. ${ }^{29}$ The primary outcome variable was treatment response based on morning stiffness, back pain, and doctor and patient global assessments. In this trial, SSZ was given at a lower dose of 2 $\mathrm{g}$ /day. The trial found SSZ to be no more effective than placebo; treatment response rates were $38.2 \%$ for SSZ versus $36.1 \%$ for placebo. Significant treatment efficacy was not shown for any of the following four outcome measures used to define treatment response: doctor global assessment (SSZ, 53.4\% $v$ placebo, 55.6\%); patient global assessment (SSZ, $40.5 \% v$ placebo, $42.1 \%$ ); morning stiffness (SSZ, $48.9 \% v$ placebo, $44.4 \%$ ); back pain (SSZ, $23.7 \% v$ placebo, $27.1 \%$ ). Premature discontinuation rates due to adverse events were $8 \%$ (11/ $131)$ and 5\% (6/133) for SSZ and placebo, respectively.

A re-analysis of a series of randomised, double blind, placebo controlled, 36 week multicentre trials of SSZ ( $2 \mathrm{~g} /$ day $)$ (including the above study) on the axial and peripheral articular manifestations of AS $(n=264)$, psoriatic arthritis $(n=221)$, and reactive arthritis $(n=134)$ was recently reported..$^{30}$ A total of 187 patients had only axial manifestations, and 432 patients had peripheral articular manifestations. The primary outcome measure was treatment response, determined on the basis of improvement in four outcome measures: patient and doctor global assessments (all patients), morning stiffness and back pain in patients with axial manifestations, and joint pain/tenderness scores and joint swelling scores in patients with peripheral articular manifestations). Intention to treat analysis showed that SSZ provided significant improvement in patients with peripheral articular involvement; response rates were $59.0 \%$ in patients treated with SSZ versus $42.7 \%$ in the placebo group $(p=0.0007)$. In contrast, in patients with axial involvement only, SSZ was ineffective; the placebo group had a higher (but not significantly different) response rate $(43.3 \%)$ than the SSZ group $(40.2 \%)$.

Adverse effects, which may often be dose or treatment limiting, may undermine the therapeutic effectiveness of SSZ. ${ }^{2}$ Common adverse effects include malaise, nausea, vomiting, anorexia, heartburn, and epigastric distress. ${ }^{31}$ Hypersensitivity reactions occur rarely; these include cutaneous reactions, the most serious being toxic epidermal necrolysis and StevensJohnson syndrome; hepatotoxic symptoms; and haematological abnormalities (including agranulocytosis, neutropenia, thrombocytopenia, and megaloblastic anaemia). Most of these reactions respond to drug withdrawal, although corticosteroid treatment may be required occasionally. Sperm abnormalities have been reported in about $80 \%$ of male recipients; these often lead to reduced male fertility, ${ }^{31}{ }^{32}$ which is especially troublesome for the generally younger male AS population.

\section{Mesalazine}

Sulfasalazine is a dimer of sulfapyridine (SP) and mesalazine (MES, 5-acetylsalicylic acid, or 5-ASA) that is cleaved into its two moieties by large-intestine bacteria. SP is systemically absorbed and has been shown to be the active moiety in RA. ${ }^{33}$ The other dimer of SSZ, MES, remains in the bowel and is the active component in inflammatory bowel disease. ${ }^{34}$ Because bowel disturbances appear to be of major importance in the development of SpA, it has been suggested that MES may be more effective than SSZ in the treatment of SpA and may possibly cause less side effects.

Taggart et al compared the efficacy of SSZ (2 g/day) with its two moieties, SP (1.25 g/day) and 5-ASA $800 \mathrm{mg} /$ day (in the form of delayed release MES (Asacol; Procter \& Gamble Pharmaceuticals, USA) in 90 patients with active AS in a randomised controlled 26 week study. ${ }^{35}$ Outcome measures included several clinical and laboratory variables, and patient's and doctor's global assessments of efficacy. Results showed no significant changes in any measures of disease activity in the MES group; significant reductions in immunoglobulin IgG, IgA, and IgM levels with SP treatment; and significant reductions in plasma viscosity, IgG, and IgA levels, nocturnal spinal pain, and overall spinal pain with SSZ. Patients and observers reported favourable outcomes significantly more often in those in the SSZ and SP groups than in those in the MES group. The global assessments showed no significant difference between SSZ and SP, whereas significant differences in favour of SSZ and SP were seen compared with 5-ASA (MES) $(\mathrm{p}<0.05$ for both comparisons $)$. Withdrawal rates were high in all three groups (28\% for SSZ, $41 \%$ for SP, $71 \%$ for MES).

Conflicting reports have come from clinical studies of other MES formulations. A 16 week open label study using another formulation of MES (Pentasa; Shire, USA) at a dose of 1.5 $\mathrm{g} /$ day showed clinically significant $(\mathrm{p}<0.02)$ improvements in all primary outcome measures (morning stiffness, Dougados functional index, patient and doctor global assessments, and ESR) in 29/30 patients with active AS who completed the study. Significant improvement was also seen in the severity of stiffness, quality of sleep, number of night awakenings, severity of pain, peripheral joint counts, and enthesis count $(\mathrm{p} \leqslant 0.04){ }^{36}$

A second open trial also demonstrated efficacy using the same MES formulation (Pentasa; Shire, USA). ${ }^{37}$ In this study, 20 patients with SpA were switched from their current SSZ treatment to MES (group A), and 19 patients with active SpA received MES without prior SSZ treatment (group B). Outcome measures included patient's and doctor's global assessments, and ESR. Doctor's assessments showed a response rate to MES of $85 \%$ compared with previous SSZ treatment in group A and $89 \%$ in group B. MES had no significant effect on ESR or patient's global assessment in group A, whereas the ESR was significantly reduced in group B (from 35 to $27 \mathrm{~mm} / \mathrm{lst} \mathrm{h} ; \mathrm{p}=0.011$ ). No treatments were discontinued prematurely, and the incidence of side effects was very low.

In contrast, in an open label, 24 week study of 20 patients with AS a third formulation of MES given at a higher dose of 3-4 g/day (Salofalk; Merck, USA) demonstrated little efficacy and caused a high number of adverse effects. ${ }^{38}$ MES produced no significant improvement in the Bath Ankylosing Spondylitis Disease Activity Index (BASDAI), BASFI, or Bath AS Metrology Index (BASMI) scores, or in patient's or doctor's global assessments. The only notable significant improvement was in ESR $(p=0.03)$. Fifteen of 20 patients $(75 \%)$ reported side effects, primarily gastrointestinal symptoms (nausea, abdominal pain, diarrhoea); four patients reported central nervous system symptoms (dizziness, headache).

Thus, available data indicate that SSZ may be beneficial in $\mathrm{SpA}$, with a greater effect on peripheral arthritis. Its efficacy in AS has not been conclusively demonstrated. Similarly, there is no conclusive evidence to support the efficacy of MES in AS. Different formulations of MES have produced mixed results. Furthermore, both SSZ and MES cause high incidences of adverse effects that potentially limit treatment.

Gold salts, antimalarial drugs, azathioprine

Despite the large number of anecdotal case studies reported, gold salts and antimalarial drugs have not been shown to be efficacious according to guidelines of clinical practice. ${ }^{39}{ }^{40}$ Azathioprine treatment is also limited. In a recent double blind trial involving 32 patients with AS, azathioprine was associated with a low response rate (only $4 / 6$ patients) and a high withdrawal rate due to side effects (12/18 patients 
Degree of sacroiliac inflammation

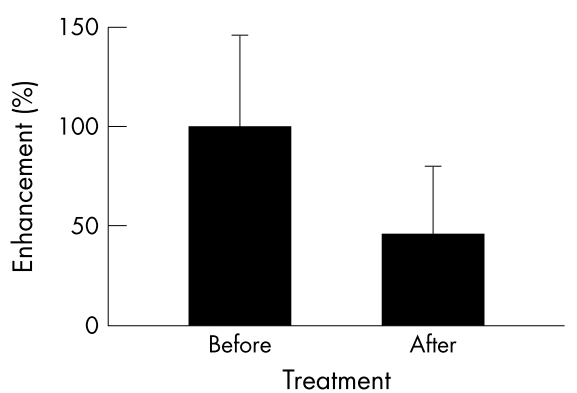

Degree of back pain

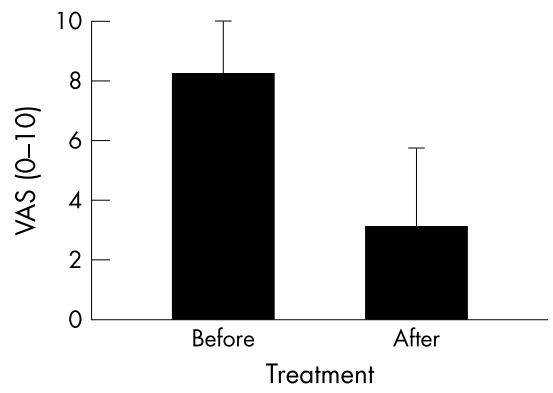

Figure 4 A study of the efficacy of CT guided intra-articular triamcinolone $40 \mathrm{mg}$ injections in SpA related sacroiliitis shows that a clear improvement of MRI proven sacroiliitis and inflammatory back pain occurred. ${ }^{50} \mathrm{~A}$ statistically significant improvement was measured in $25 / 30$ (83\%) patients with disease subjectively lasting 8.9 (SD 5.3) months. Sacroiliac inflammation was assessed by diagnostic MRI, and subjective back pain was assessed on a VAS ( $0=$ no pain; $10=$ very severe pain) before and after treatment. Adapted and reprinted, with permission from the authors and the Journal of Rheumatology, from reference 50. Copyright (C) 1996 Journal of Rheumatology.

$(67 \%)) \cdot{ }^{41}$ Indeed, the use of azathioprine has been limited by its association with serious adverse effects, primarily myelotoxicity (for example, leucopenia, megalobastic anaemia). ${ }^{41-43}$ A concern about the long term use of azathioprine is its potential for neoplastic disease, based on the observation of azathioprine-induced reversible chromosomal abnormalities in humans. ${ }^{31}$

A case report ${ }^{44}$ and an open study ${ }^{45}$ have reported symptomatic improvement after treatment with oral or intramuscular methotrexate in patients with AS refractory to first line treatment. However, the efficacy of methotrexate treatment has not been demonstrated in large placebo controlled trials. The first randomised, controlled study of severe AS treated with methotrexate showed no significant benefit of this agent compared with placebo, even in patients with peripheral arthritis. ${ }^{46}$

\section{Corticosteroids}

Physical therapy and NSAIDs are effective treatments during painful periods of AS, but they do not always provide total pain relief. The inflammatory back pain and sacroiliitis associated with AS are, in some cases, resistant to these interventions. Corticosteroid treatment may provide rapid and considerable relief, but few published reports are found of their use in AS. Oral administration of corticosteroids at conventional doses is of little value in AS, and long term use of corticosteroids is associated with serious adverse effects affecting almost every major body system. These include bone metabolism abnormalities, glucose and lipid metabolism, cutaneous abnormalities, cataracts, and gastrointestinal complications. ${ }^{47}$ In AS refractory to NSAIDs, corticosteroid intravenous (IV) pulse therapy can provide rapid temporary symptomatic improvement.

\section{Corticosteroid intravenous pulse therapy}

Corticosteroid IV pulse therapy has been shown to improve clinical disease activity in AS. In a study conducted in 1983, eight patients with NSAID refractory active AS received $1 \mathrm{~g}$ of methylprednisolone IV on three consecutive days. ${ }^{48}$ All clinical measurements (early morning stiffness, pain, and overall spinal movement) were improved within one week, with significant reductions in early morning stiffness $(\mathrm{p}<0.05)$ and pain $(\mathrm{p}<0.02)$. However, improvement in overall spinal movement did not reach significance until four weeks after pulse therapy $(p=0.02)$. Moreover, deterioration in disease activity measurements to pre-pulse levels was seen by 12 weeks, with the exception of pain, which remained significantly better $(\mathrm{p}<0.05)$. A significant decrease in mean ESR and $\mathrm{C}$ reactive protein (CRP) was seen at one week after pulse methylprednisolone administration $(\mathrm{p}<0.01)$. Sleeplessness and a metallic taste in the mouth were the only side effects reported and were limited to the three days of pulse therapy.
A double blind study of 17 patients with active NSAID refractory AS compared the efficacy of a high $(1000 \mathrm{mg})$ and low $(375 \mathrm{mg}$ ) IV dose of methylprednisolone, each dose being given on three consecutive days. ${ }^{49}$ None of the patients had total spinal ankylosis. Methylprednisolone treatment provided a rapid improvement in pain (VAS) and spinal mobility (Schober's test). No statistically significant differences were found between the two doses, but the higher dose tended to provide a greater and longer lasting improvement in pain. Regression line analysis showed that the high dose group would reach its pretreatment pain levels in 347 days compared with 253 days in the low dose group. Additionally, patients in the high dose group were controlled without re-institution of analgesic or NSAID treatment for an average of 25 days compared with an average of eight days for those in the lower dose group. No serious adverse events were reported during the 180 days of the study.

\section{Intra-articular corticosteroid injection}

Local treatment of an inflamed joint with a corticosteroid can provide rapid and longlasting relief. The joint most commonly affected by AS, the sacroiliac joint, has a complicated anatomy that is difficult to access; therefore, this method has not been commonly used in AS. ${ }^{51}$ However, modern technology has made intra-articular injection more feasible in this group of patients.

Recent studies have reported successful sacroiliac joint injection with the assistance of CT. In one study MRI showed clearly improved sacroiliitis and inflammatory back pain in 25/30 (83\%) patients with SpA that subjectively lasted for 8.9 months after CT guided injections of triamcinolone acetonide $(40 \mathrm{mg})$ into inflamed sacroiliac joints (fig 4). ${ }^{50}$ Similar benefit was reported in another study employing dynamic MRI guidance of triamcinolone acetonide $(40 \mathrm{mg})$ injections in nine patients ( 16 joints were injected) with symptomatic, NSAID refractory SpA and subchondral bone marrow oedema proved by MRI..$^{52}$ All patients had persistent, poorly controlled sacroiliitis and inflammatory back pain. Subjective improvement that lasted for a mean of 10.8 months was reported by $7 / 9$ $(78 \%)$ patients. Follow up MRI showed resolution of subchondral bone marrow oedema in $8 / 9(89 \%)$ patients at three months. No side effects were reported.

Only one double blind study assessing the efficacy of intraarticular corticosteroid injection in SpA has been published..$^{53}$ Under fluoroscopic control and after arthrography, six joints were injected with prednisolone $(62.5 \mathrm{mg})$, and seven joints with placebo ( 13 articulations from 10 patients with painful sacroiliitis). At one month, patients injected with corticosteroid reported $>70 \%$ relief in five of the six injected joints (fig 5); $81 \%$ of the sacroiliac joints improved. None of the joints treated with placebo improved. Despite some relapses, results were still favourable at six months, with improvement in $58 \%$ of the sacroiliac joints. 


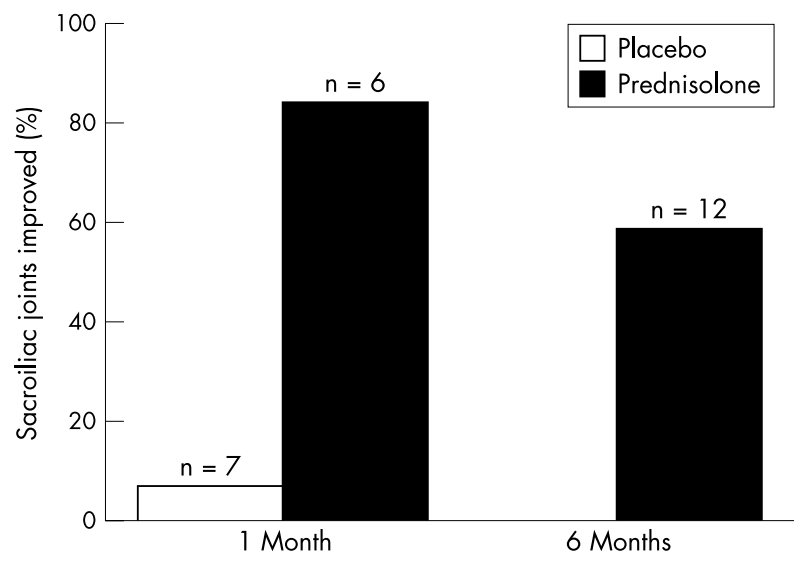

Figure 5 Efficacy of prednisolone $62.5 \mathrm{mg}$ versus placebo injections of sacroiliac joints in 10 patients with SpA confirms that corticosteroid injections of inflamed sacroiliac joints are effective. ${ }^{53}$ $n=$ number of joints. This previously unpublished figure is based on data published by $\operatorname{Dr} Y$ Maugars et al in the British Journal of Rheumatology and is printed with the authors' permission.

In summary, to date, no studies have been performed to evaluate the effectiveness of continuous oral corticosteroid treatment in AS. According to clinical experience, such treatment is clearly less effective in AS than in RA. Available data indicate that pulse corticosteroid therapy can induce substantial improvement for two months up to one year and that corticosteroid injection of the sacroiliac joint, guided by arthrography, CT, or MRI is safe and effective in the reduction of inflammatory back pain.

\section{Bisphosphonates}

Bisphosphonates are potent inhibitors of osteoclastic bone resorption and delayed-type hypersensitivity chronic inflammation..$^{55}$ The ability selectively to localise in bone tissue and reduce inflammation has made these drugs useful in the treatment of osteoporosis and metastatic bone disease. ${ }^{5657}$ Bisphosphonates have been shown to reduce chronic inflammation and pathological mineralisation in animal models of arthritis. $^{58} 59$

\section{Pamidronate}

Studies of the aminobisphosphonate, pamidronate, have produced mixed results in suppressing inflammation in patients with RA. ${ }^{60}$ The evaluation of pamidronate in patients with AS was prompted by the observation that bisphosphonates suppress inflammation and cartilage/bone erosion in murine models of RA.

In a preliminary open study, the anti-inflammatory properties of pamidronate were evaluated in 16 patients with NSAID refractory active AS. ${ }^{62}$ The patients were randomly allocated to receive either IV pamidronate $30 \mathrm{mg}$ once a month for three months, followed by $60 \mathrm{mg}$ once a month for an additional three months (group 1), or IV pamidronate $60 \mathrm{mg}$ dose once a month for three months (group 2). Clinical outcome assessments included the BASDAI for measurement of disease severity, BASFI for measurement of functional impairment, and BASMI for measurement of spinal mobility. In the study group as a whole, the mean BASDAI baseline score was 6.7. Effects of the drug were delayed, and benefits of treatment were not seen before three months. Group 1 showed significant improvements in BASDAI and BASMI scores $(\mathrm{p}<0.03$ for both $)$ and in the ESR $(\mathrm{p}=0.009)$. Group 2 showed a significant improvement only in the BASMI ( $p=0.007)$, with no significant change in BASDAI score or ESR. However, pamidronate-induced improvement appeared to be long lasting, with positive response reported even four months after the final infusion. Adverse events do not appear to be a major concern with this agent, although some patients may develop acute arthralgia, myalgia, and pyrexia after the first IV infusion of pamidronate, but generally not with subsequent infusions. ${ }^{63}$ The reactions are generally mild and last 24-48 hours.

A second preliminary open study of pulse IV pamidronate treatment demonstrated significant improvements in all clinical and laboratory variables. ${ }^{64}$ Nine patients with NSAID refractory peripheral SpA (five had AS, three had undifferentiated $\mathrm{SpA}$, and one had reactive arthritis) received IV infusions of pamidronate $60 \mathrm{mg}$ on days $1,2,14,28$, and 56 of the study and were assessed up to 84 days. Reductions of $44 \%$ $(p=0.028), 47 \%(p=0.015)$, and $42 \%(p=0.011)$ were reported in the BASDAI, BASFI, and the Bath AS Global Index (BASGI) scores, respectively. Mean swollen and tender joint count decreased by $93.8 \%(p=0.017)$ and $98.2 \%(p=0.012)$, respectively. ESR decreased by $49.4 \%(\mathrm{p}=0.012)$.

A placebo controlled evaluation of IV pamidronate is not feasible because many patients develop, as previously noted, transient arthralgias and myalgias after the first IV infusion, thereby compromising blinding. Thus, a randomised, double blind trial comparing $60 \mathrm{mg}$ versus $10 \mathrm{mg}$ IV doses of pamidronate was conducted in 84 patients with NSAID refractory AS (mean disease duration, 15.1 years).$^{65}$ Inclusion criteria included BASDAI $\geqslant 4$ or morning stiffness for $\geqslant 45$ minutes despite NSAID treatment, and absence of end stage ankylosis. Patients had to be receiving stable doses of an NSAID (for four weeks) at study entry. Stable second line treatment (three months) and/or corticosteroids (one month) were permitted. IV pamidronate $60 \mathrm{mg}(\mathrm{n}=41)$ and $10 \mathrm{mg}(\mathrm{n}=43)$ was given monthly for six months. The primary outcome measure was the BASDAI; secondary outcome measures included the BASFI, BASGI, BASMI, ESR, CRP level, and percentage of patients achieving a reduction of $\geqslant 25 \%$ in the BASDAI.

At six months, significant reductions were seen in the BASDAI $(p=0.002)$, BASFI $(p<0.001)$, BASGI $(p=0.01)$, and BASMI $(p=0.03)$ in the $60 \mathrm{mg}$ group, compared with the 10 mg group (fig 6). At six months, the mean BASDAI had decreased by 2.22 from a baseline score of 6.4 in the $60 \mathrm{mg}$ group $(-34.5 \%)$, compared with a decrease of only 0.93 from a baseline score of 6.2 in the $10 \mathrm{mg}$ group $(-15 \%$; $\mathrm{p}=0.002)$. Axial pain and morning stiffness were also significantly reduced $(\mathrm{p}=0.003)$. Peripheral pain assessments in the two groups were not significantly different, which may be explained by the short circulating half life of IV pamidronate (that is, about one hour) that may result in low levels in the peripheral blood. Significantly more patients receiving the 60 $\mathrm{mg}$ dose achieved a reduction of $\geqslant 25 \%$ in the BASDAI, compared with those receiving the $10 \mathrm{mg}$ dose $(63.4 \%$ v $30.2 \%$, respectively; $\mathrm{p}=0.004)$. No significant differences between treatments were seen in ESR or CRP levels. Sixty three per cent of patients in the $60 \mathrm{mg}$ group responded to IV pamidronate according to the ASAS $20 \%$ improvement criteria by six months, compared with $27 \%$ of those in the $10 \mathrm{mg}$ group. A lower withdrawal rate was reported in the $60 \mathrm{mg}$ group $(7.3 \%)$ than in the $10 \mathrm{mg}$ group $(20.9 \%)$. Adverse events were limited to transient arthralgias/myalgias after the initial infusion, which occurred in $68.3 \%$ and $46.5 \%$ of patients receiving the $60 \mathrm{mg}$ and $10 \mathrm{mg}$ doses, respectively ( $\mathrm{p}=\mathrm{NS}$ ).

Side effects of pamidronate include transient asymptomatic hypocalcaemia, transient lymphopenia, bone pain, and infusion site reactions. ${ }^{6466}$

Further evaluation of pamidronate is needed to determine appropriate doses and dosing schedules, the efficacy of oral treatment, effects on structural damage, the effect on early AS, and its use in combination with other treatments. The efficacy of oral treatment with more potent bisphosphonates (for example, alendronate, risedronate) also warrants investigation. 


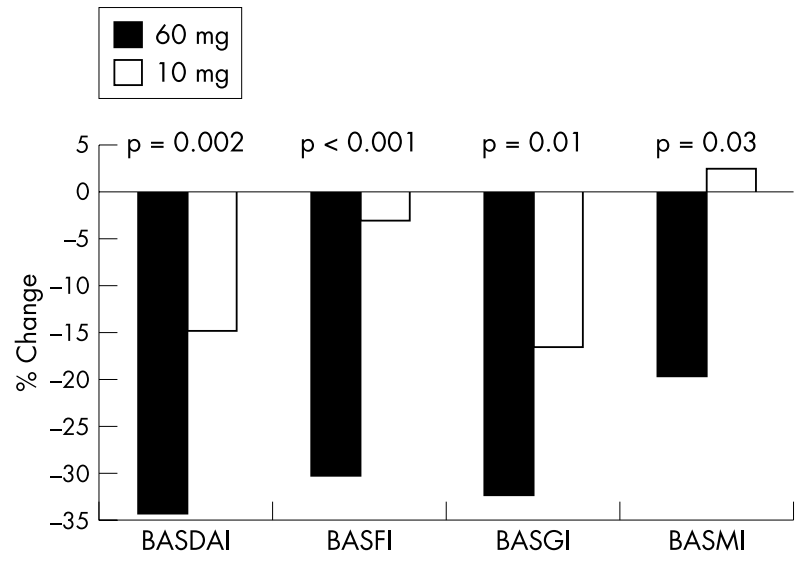

Figure 6 Effects of pamidronate on clinical outcomes in AS at six months. ${ }^{65}$ Adapted and reprinted, with permission from the authors and Wiley-Liss, Inc, a subsidiary of John Wiley and Sons, Inc, from reference 65 . Copyright (C) 2002 Wiley-Liss.

\section{PHYSICAL THERAPY, EXERCISE, AND EDUCATION}

The goals of physical treatment of AS are to improve mobility and strength and to prevent or reduce spinal curve abnormalities. Physical treatments, including physical therapy and regular exercise, contribute to AS management but cannot replace pharmacotherapy. However, physical treatments and medical treatment are mutually complementary. Most physical exercise is impossible until pain and inflammation are medically controlled. However, stiffness and spinal deformities cannot be prevented by drugs alone. ${ }^{2}$

\section{Physical therapy approaches}

Physical therapy including exercise is a necessary adjunct to pharmacotherapy. However, the lack of controlled data makes it difficult to identify the best application of these interventions. Dagfinrud and Hagen recently reviewed the available scientific evidence up to February 2000 from clinical evaluations of physical therapy and exercise in AS. ${ }^{67}$ Three studies were included in the review of 241 patients with AS on the basis of the following criteria: patients had AS based on the New York criteria; at least one of the comparison groups received physical therapy; and main outcomes were spinal mobility, pain, stiffness, physical function, and global assessment of change. ${ }^{68-70}$

Two of these studies ( $n=144, n=44)$ compared the effect of a home exercise programme with supervised group physical therapy ${ }^{6869}$ The differences reported were in favour of the supervised group for improvements in global health and functioning, and pain and stiffness. The changes from baseline in pain and stiffness measurements were $50 \%$ better for the supervised patients than for those exercising at home. The third study $(n=53)$ compared a programme of supervised home physical therapy and exercise coupled with disease education with no intervention over four months. ${ }^{70}$ The improvements in spinal mobility (as measured by fingertip to floor distance) and function were significantly better in the patients receiving treatment and education than in those receiving no intervention $(\mathrm{p}<0.004$ for both parameters $)$. It was concluded that physiotherapy with disease education is an effective intervention in patients with AS. The available data support positive effects of physiotherapy in the management of AS. However, further research is needed to determine the most effective physiotherapy modalities and applications and to establish the precise role of physiotherapy interventions for AS.

\section{Spa treatment}

A recently conducted Dutch study evaluated the efficacy of three weeks of combined spa exercise treatment as an adjunct to standard treatment with drugs and weekly group physical therapy in patients with AS. ${ }^{71}$ Two groups of 40 patients each were randomly allocated to treatment at two different spas (one in Austria, the other in the Netherlands). A control group $(n=40)$ stayed at home and received weekly group treatment for 40 weeks. The "spa" patients followed a regimen of combined spa/group physical exercises for three weeks, followed by weekly group physical therapy for an additional 37 weeks. The improvements in function and global wellbeing in the groups receiving spa exercise treatment were greatest early in the study. At four weeks after the start of spa exercise treatment, significant improvements were seen in the pooled index of change (which was an aggregate of the following primary outcomes: BASFI, patient's global wellbeing, pain, and duration of morning stiffness) in the "spa" group, compared with the control group $(\mathrm{p} \leqslant 0.004)$. Benefit was maintained over the 40 week study period in patients receiving spa exercise treatment, although by 40 weeks, the improvement in the pooled index of change had lost statistical significance, as compared with controls.

The cost effectiveness of combined spa exercise treatment has been assessed in a randomised controlled trial described by van Tubergen et al..$^{72}$ The incremental cost effectiveness and cost-utility ratios of the three week course of spa exercise treatment were compared with standard treatment. Direct (healthcare and non-healthcare) and indirect (nonhealthcare) costs were included. The incremental cost effectiveness for each unit effect gained in functional ability on a 0-10 scale (based on the BASFI) was 1269 euros and 2477 euros, respectively, for the two groups who received spa exercise treatment. The costs for each quality adjusted life year gained (assessed by the EuroQol) were 7465 euros and 18575 euros for the two groups, respectively. No substantial changes in the cost ratios were found in sensitivity analyses.

\section{Patient education}

The patient diagnosed with AS must receive education about the nature of the disease and treatment options. Education clarifies the rationale and benefits of drug treatment and different methods of drug administration, as well as the long term benefits of continuous physiotherapy on back pain. Informing the patient about the possible occurrence of spinal ankylosis may reinforce compliance with drug treatment regimens and physiotherapy. Inpatient or outpatient education programmes reinforced with informative pamphlets may also be helpful.

Choosing the optimal mode of administration of physical therapy is often difficult. Several approaches may assist the patient in making choices: a simple explanation by the doctor; provision of a booklet including examples of home exercises; referral for physiotherapy, either for patients as a group or individually; referral to a spa; or attendance (possibly as an inpatient) at a rehabilitation centre.

\section{SURGICAL INTERVENTION}

Surgery may become necessary in some cases of AS. The mechanisms responsible for the ossification of ligaments and joints that causes fusion of the spinal column have not been established. As a result of this process, the fused vertebrae become a long bone housing for the spinal cord, limiting movement and elasticity. The reduction in flexibility renders the spine susceptible to a variety of disorders, including fracture and dislocation, atlantoaxial and atlanto-occipital subluxation, spinal deformity, spinal stenosis, and hip disease. ${ }^{27}$ When these complications occur, surgical intervention may be required.

\section{Spinal fractures}

Initial management of spinal fractures may be achieved with halo vest immobilisation. Surgical intervention is indicated when neurological involvement becomes apparent. ${ }^{73}$ 


\section{Rotary instability}

Atlantoaxial and atlanto-occipital subluxation may be monitored over a long period before surgery is recommended. Even in the absence of neurological signs, surgical fusion may be necessary if subluxation progresses notably and the patient has severe pain and instability. ${ }^{74}$

\section{Spinal deformity}

A single, well accepted clinical score is not yet available for assessing spinal deformity and facilitating decision-making about surgical treatment. Thoracolumbar kyphotic deformity resulting from AS is corrected using three different operative techniques: opening wedge osteotomy, polysegmental wedge osteotomy, and closing wedge osteotomy. In a structured review of the literature from 1945 to 1998, Van Royen reported an average correction ranging from 37 to 40 degrees with surgical intervention. ${ }^{75}$ Loss of correction was reported in some cases, mainly in patients treated by open wedge osteotomy or polysegmental wedge osteotomies. All three techniques were associated with neurological complications. Perioperative mortality was $4 \%$; pulmonary, cardiac, and intestinal problems were the major causes of fatal complications.

\section{Hip disease}

Hip involvement is common in patients with AS, particularly those with early disease onset. The duration of joint survival in young active patients undergoing arthroplasty is a particular concern. Sweeney et al recently evaluated the outcome of this procedure in a follow up study of 166 patients with AS who had undergone total hip arthroplasty (THA).$^{76}$ Assessment variables included disease activity (BASDAI), function (BASFI), and global wellbeing (Bath AS Global). These were compared in the THA group and a control group of patients with AS who had not undergone THA and who were matched for age, sex, and disease duration. The mean age of AS onset was 19.5 years for the THA group, compared with 24.4 years for the control group; the mean age at the first THA was 40.0 years. The mean follow up period for the THA group was 14 years. Overall, the patients with THA considered the outcome to be very good for $85 \%$ of the surgeries. However, compared with matched controls, patients undergoing THA had comparable scores on the BASDAI but had significantly poorer function $(p<0.05)$ and lower global wellbeing $(p<0.05)$. Rates of survival of the original THA after 10, 15, and 20 years were $90 \%, 78 \%$, and $60 \%$, respectively, indicating long term joint survival.

A Mayo Clinic review of 33 patients with AS requiring surgical intervention from 1984 to 1989 emphasises the fragility of the ankylosed spinal column. ${ }^{74}$ Extreme care must be taken when moving or positioning patients to prevent fracture or dislocation. A wide range of spinal disorders associated with the disease often progress to the point that surgery becomes necessary despite its inherent risks. Thorough radiological evaluation, cautious endotracheal intubation and halo vest application, early surgical stabilisation, and postoperative external orthoses are all critical to prevent further spinal cord injury. Outcome can be favourable with early diagnosis and proper management.

\section{CONCLUSIONS}

Despite the diversity of conventional treatments available for the treatment of AS, no optimal treatment plan has emerged to date. Current treatment options are palliative at best, providing no alteration of the disease process. To date, no drugs with disease controlling properties are available for the treatment of AS. Physical therapy and exercise to improve mobility, fitness, and overall health, combined with NSAID administration to control pain and inflammation, are the most widely prescribed treatments. The paucity of carefully controlled clinical trials evaluating the efficacy of physical therapy and exercise modalities makes it difficult for doctors to identify the best mode of administration of these interventions and to justify the long term costs. When a patient becomes refractory to NSAIDs, or has intolerable side effects from the drugs, alternative treatments must be sought. Various second line drugs, such as DMARDs, corticosteroids, and bisphosphonates, may be prescribed, although most of these agents have not been comprehensively evaluated. When structural damage becomes severe enough, surgical intervention may be warranted. However, the fragility of the ankylosed spinal column and damaged joints poses a challenge to any surgical procedure. For patients with AS, the future of successful treatment lies in identifying those patients at risk for severe, progressive disease early in the disease course and in the development of new pharmacological interventions capable of altering the disease course by halting or slowing progressive structural damage, in addition to controlling symptoms.

\section{Authors' affiliations}

M Dougados, Department of Rheumatology, René Descartes University, Hôpital Cochin, Paris, France

B Dijkmans, Department of Rheumatology, VU University Medical Centre, Amsterdam, The Netherlands

M Khan, Case Western Reserve University, Cleveland, Ohio, USA W Maksymowych, Faculty of Medicine and Dentistry, University of Alberta, Edmonton, Alberta, Canada

Si van der Linden, Department of Medicine, Division of Rheumatology, University Hospital Maastricht, Maastricht, The Netherlands

J Brandt, Department of Gastroenterology and Rheumatology, UKBF,

Free University, Berlin, Germany

\section{REFERENCES}

1 Dougados M. Treatment of spondyloarthropathies. Recent advances and prospects in 2001. Joint Bone Spine 2001;68:557-63

2 Dougados M, Revel M, Khan MA. Spondyloarthropathy treatment: progress in medical therapy. Baillieres Clin Rheumatol 1998;12:717-36.

3 Dougados M, Caporal R, Doury P, Thiesce A, Pattin S, Laffez B, et al. A double blind cross over placebo controlled trial of ximoprofen in ankylosing spondylitis. J Rheumatol 1989;16:1167-9.

4 Dougados $M$, Behier JM, Jolchine I, Calin A, van der Heijde D, Olivier I, et al. Efficacy of celecoxib, a cyclooxygenase 2-specific inhibitor, in the treatment of ankylosing spondylitis: a six-week controlled study with comparison against placebo and against a conventional nonsteroidal antiinflammatory drug. Arthritis Rheum 2001;44:180-5.

5 Dougados $M$, Nguyen M, Caporal R, Legeais J, Bouxin-Sauzet $A$ Pellegri-Guegnault B, et al. Ximoprofen in ankylosing spondylitis. Scand J Rheumatol 1994;23:243-8.

6 Calin A, Grahame R. Double-blind crossover trial of flurbiprofen and phenylbutazone in ankylosing spondylitis. BM 1974;4:496-9.

7 Tannenbaum H, De Coteau WE, Esdaile JM. A double blind multicentre trial comparing piroxicam and indomethacin in ankylosing spondylitis with long-term follow-up. Curr Ther Res 1984;36:425-35.

8 Sturrock RD, Hart FD. Double-blind crossover comparison of indomethacin, flurbiprofen and placebo in ankylosing spondylitis. Ann Rheum Dis 1974;33:129-31.

9 Amor B, Dougados M, Listrat V, Menkes CJ, Dubost JJ, Roux H, et al. Evaluation des critères de spondylarthropathies d'Amor et de l'European Spondylarthropathy Study Group (ESSG). Une etude transversale de 2228 patients. Ann Med Interne (Paris) 1991;142:85-9.

10 Moreland LW, Russell AS, Paulus HE. Management of rheumatoid arthritis: the historical context. J Rheumatol 2001;28:1431-52.

11 Coles LS, Fries JF, Kraines RG, Roth SH. From experiment to experience: side effects of nonsteroidal anti-inflammatory drugs. Am J Med 1983;74:820-8.

12 Paulus HE. FDA arthritis advisory committee: serious gastrointestina toxicity of nonsteroidal antiinflammatory drugs, etc. Arthritis Rheum 1988;31:1450-1

13 Silverstein FE, Graham DY, Senior JR, Davies HW, Struthers BJ, Bittman $\mathrm{RM}$, et al. Misoprostol reduces serious gastrointestinal complications in patients with rheumatoid arthritis receiving nonsteroidal anti-inflammatory drugs. Ann Intern Med 1995;123:241-9.

14 Rostom A, Wells G, Tugwell P, Welch V, Dube C, McGowan J. Prevention of NSAID-induced gastroduodenal ulcers (Cochrane review). In: The Cochrane Library. Oxford:Update Software, 2001 :Issue 3

15 Simon LS, Weaver AL, Graham DY, Kivitz AJ, Lipsky PE, Hubbard RC, et al. Anti-inflammatory and upper gastrointestinal effects of celecoxib in rheumatoid arthritis: a randomized controlled trial. JAMA 1999;282:1921-8. 
16 Silverstein FE, Faich G, Goldstein JL, Simon LS, Pincus T, Whelton A, et al. Gastrointestinal toxicity with celecoxib vs nonsteroidal anti-inflammatory drugs for osteoarthritis and rheumatoid arthritis: the CLASS study: a randomized controlled trial. JAMA 2000;284:1247-55

17 Hawkey C, Laine L, Simon T, Beaulieu A, Maldonado-Cocco J, Acevedo $E$, et al. Comparison of the effect of rofecoxib la cyclooxygenase 2 inhibitor), ibuprofen, and placebo on the gastroduodenal mucosa of patients with osteoarthritis: a randomized, double-blind, placebo-controlled trial. The Rofecoxib Osteoarthritis Endoscopy Multinational Study Group. Arthritis Rheum 2000;43:370-7.

18 Langman MJ, Jensen DM, Watson DJ, Harper SE, Zhao P-L, Quan H, ef al. Adverse upper gastrointestinal effects of rofecoxib compared with NSAIDs. JAMA 1999;282:1929-33.

19 Mukheriee D, Nissen SE, Topol EJ. Risk of cardiovascular events associated with selected COX-2 inhibitors. JAMA 2001;286:954-9

20 Peterson WL, Cryer B. COX-1-sparing NSAIDs - Is the enthusiasm justified? JAMA 1999:282:1961-3.

21 Amor B, Dougados M, Mijiyawa M. Criteria of the classification of spondyloarthropathies. Rev Rhum Mal Osteoartic 1990;57:85-9

22 van der Heijde D, Bellamy N, Calin A, Dougados M, Khan MA, van der Linden S. Preliminary core sets for endpoints in ankylosing spondylitis. Assessments in Ankylosing Spondylitis Working Group. J Rheumatol 1997; 24:2225-9.

23 van der Heijde D, Calin A, Dougados M, Khan MA, van der Linden S, Bellamy N. Selection of instruments in the core set for DC-ART, SMARD, physical therapy, and clinical record keeping in ankylosing spondylitis. Progress report of the ASAS Working Group. Assessments in Ankylosing Spondylitis. J Rheumatol 1999;26:951-4

24 Anderson JJ. Baron G, van der Heijde D, Felston DT, Dougados M. Ankylosing spondylitis assessment group preliminary definition of short-term improvement in ankylosing spondylitis. Arthritis Rheum 2001:44:1876-86.

25 Dougados M, Gueguen A, Nakache JP, Velicitat P, Veys EM, Zeidler H, et al. Ankylosing spondylitis: what is the optimum duration of a clinical study? A one year versus a six week nonsteroidal anti-inflammatory drug trial. Rheumatology (Oxford) 1999;38:235-44.

26 Laasila K, Leirisalo-Repo M. Side effects of sulphasalazine in patients with rheumatic diseases or inflammatory bowel disease. Scand J Rheumatol 1994;23:338-40.

27 Ferraz MB, Tugwell P, Goldsmith CH, Atra E. Meta-analysis of sulfasalazine in ankylosing spondylitis. J Rheumatol 1990;17:1482-6.

28 Dougados $M$, van der Linden S, Leirisalo-Repo $M$, Huiffeldt $B$, Juhlin $R$, Zeidler $\mathrm{H}$, et al. Sulfasalazine in the treatment of spondyloarthropathy. A randomized, multicenter, double-blind, placebo-controlled study. Arthritis Rheum 1995;38:618-27

29 Clegg DO, Reda DJ, Weisman MH, Blackburn WD, Cush JJ, Cannon $\mathrm{GW}$, et al. Comparison of sulfasalazine and placebo in the treatment of ankylosing spondylitis: a Department of Veterans Affairs Cooperative Study. Arthritis Rheum 1996:39:2004-12.

30 Clegg DO, Reda DJ, Adbellatif M. Comparison of sulfasalazine and placebo for the treatment of axial and peripheral articular manifestations of the seronegative spondyloarthropathies: a Department of Veterans Affairs Cooperative Study. Arthritis Rheum 1999;42:2325-9.

31 Hanauer SB, Stathopoulos G. Risk-benefit assessment of drugs used in the treatment of inflammatory bowel disease. Drug Saf 1991;6:192-219.

32 Birnie GG, McLeod TIF, Watkinson G. Incidence of sulphasalazine-induced male infertility. Gut 1981:22:452-5.

33 Neumann VC, Taggert AJ, Le Gallez P, Astbury C, Hill J, Bird HA. A study to determine the active moiety of sulfasalazine in rheumatoid arthritis. J Rheumatol 1986;13:285-7.

34 Azad Khan AD, Piris J, Truelove SC. An experiment to determine the active therapeutic moiety of sulphasalazine. Lancet 1977;ii:889-92.

35 Taggart A, Gardiner P, McEvoy F, Hopkins R, Bird H. Which is the active moiety in ankylosing spondylitis? A randomized, controlled study. Arthritis Rheum 1996:39:1400-5.

36 Thomson GT, Thomson BR, Thomson KS, Ducharme JS. Clinical efficacy of mesalamine in the treatment of spondyloarthropathies. J Rheumatol 2000;27:714-18.

37 Dekker-Saeys BJ, Dijkmanns BA, Tytgat GN. Treatment of spondyloarthropathy with 5-aminosalycylic acid (mesalazine): an open trial. J Rheumatol 2000;27:723-6.

38 Van Denderen JC, Van der Horst-Bruinsma IC, Bezemer PD, Dijkmans BAC. Efficacy and safety of mesalazine (Salfofalk) in patients with ankylosing spondylitis: an open study in 20 patients. J Rheumatol 2002 (submitted).

39 Schattenkirchner $\mathbf{M}$. Indications and contraindications for systemic gold therapy. Wien Klin Wochenschr 1984;156(suppl):3-7

40 Williamson L, Illingworth, Smith D, Mowat A. Oral quinine in ankylosing spondylitis: a randomized placebo controlled double blind crossover trial. J Rheumatol 2000;27:2054-5.

41 Brandt J, Buss B, Sieper J, Braun J. Efficacy of treatment with sulfasalazine versus azathioprine in ankylosing spondylitis. J Rheumatol 2000;27(suppl 59):55

42 Durez $\mathbf{P}$, Horsmans $Y$. Dramatic response after an intravenous loading dose of azathioprine in one case of severe and refractory ankylosing spondylitis. Rheumatology (Oxford) 2000;39: 182-4

43 Lennard L, Van Loon JA, Weinshilboum RM. Pharmacogenetics of acute azathioprine toxicity: relationship to thiopurine methyltransferase genetic polymorphism. Clin Pharmacol Ther 1989;46:149-54.

44 Yamane K, Saito C, Natsuda H, Yuhara T, Akama T, Suzuki H, et al. Ankylosing spondylitis successfully treated with methotrexate. Intern Med $1993 ; 32: 53-6$
45 Biasi D, Carletto A, Caramaschi P, Pacor ML, Maleknia T, Bambara LM Efficacy of methotrexate in the treatment of ankylosing spondylitis: a hree-year open study. Clin Rheumatol 2000;19:114-17.

46 Roychaudhry B, Bintley-Bagot S, Hunt J, Tunn EJ. Methotrexate in severe ankylosing spondylitis: a randomized placebo controlled, double-blind observer study [abstract]. Rheumatology (Oxford) 2001;40(suppl):43.

47 Keenan GF. Management of complications of glucocorticoid therapy. Clin Chest Med 1997; 18:507-20

48 Richter MB, Woo P, Panayi GS, Trull A, Unger A, Shepherd P. The effects of intravenous pulse methylprednisolone on immunological and inflammatory processes in ankylosing spondylitis. Clin Exp Immunol 1983;53:51-9.

49 Peters ND, Ejstrup L. Intravenous methylprednisolone pulse therapy in ankylosing spondylitis. Scand J Rheumatol 1992;21:134-8.

50 Braun J, Bollow M, Seyrekbasan F, Haberle HJ, Eggens U, Mertz A, et al. Computed tomography guided corticosteroid injection of the sacroiliac joint in patients with spondyloarthropathy with sacroiliitis: clinical outcome and follow-up by dynamic magnetic resonance imaging J Rheumatol 1996;23:659-64

51 Bellamy N, Park W, Rooney PJ. What do we know about the sacroiliac joint? Semin Arthritis Rheum 1983;12:282-313.

52 Gunaydin I, Pereira PL, Daikeler T, Mohren M, Trubenbach J, Schick F, et al. Magnetic resonance imaging guided corticosteroid injection of the sacroiliac joints in patients with therapy resistant spondyloarthropathy: a pilot study. J Rheumatol 2000;27:424-8.

53 Maugars Y, Mathis C, Berthelot JM, Charlier C, Prost A. Assessment of the efficacy of sacroiliac corticosteroid injections in spondyloarthropathies: a double-blind study. Br J Rheumato 1996;35:767-70

54 Dunn CJ, Galinet LA, Wu H, Nugent FA, Schlachter ST, Staite ND, et al Demonstration of novel anti-arthritic and anti-inflammatory effects of diphosphonates. J Pharmacol Exp Ther 1993;266:1691-8.

55 Russell RGG, Croucher PI, Rogers M. Biphosphonates: pharmacology, mechanisms of action and clinical uses. Osteoporos Int 1999:2(suppl):S66-80.

56 Black DM, Cummings SR, Karpf DB, Cauley JA, Thompson DE, Nevitt $M C$, et al. Randomized trial of effect of alendronate on risk of fracture in women with existing vertebral fractures. Fracture Intervention Trial Research Group. Lancet 1996;348:1535-41

57 Lipton A. Bisphosphonates and breast carcinoma: present and future. Cancer 2000;88(suppl):3033-7.

58 Francis MD, Hovancik K, Boyce RW. NE-58095: a diphosphonate which prevents bone erosion and preserves joint architecture in experimental arthritis. Int J Tissue React 1989;1 1:239-52.

59 Flora L. Comparative antiinflammatory and bone protective effects of two diphosphonates in adjuvant arthritis. Arthritis Rheum 1979:22:340-6

60 Eggelmeijer F, Papapoulos SE, van Paassen HC, Dijkmans BA Breedveld FC. Clinical and biochemical response to single infusion of pamidronate in patients with active rheumatoid arthritis: a double blind placebo controlled study. J Rheumatol 1994;21:2016-20.

61 Ralston SH, Hacking L, Willocks L, Bruce F, Pitkeathly DA. Clinical, biochemical, and radiographic effects of aminohydroxypropylidene bisphosphonate treatment in rheumatoid arthritis. Ann Rheum Dis 1989;48:396-9.

62 Maksymowych WP, Jhangri GS, Leclercq S, Skeith K, Yan A, Russell AS. An open study of pamidronate in the treatment of refractory ankylosing spondylitis. J Rheumatol 1998;25:714-17.

63 Schweitzer DH, Oostendorp-van de Ruit M, van der Pluijm G, Lowik CW, Papapoulos SE. Interleukin-6 and the acute phase response during treatment of patients with Paget's disease with nitrogen-containing bisphosphonate dimethylaminohydroxypropylidene bisphosphonate. J Bone Miner Res 1995; 10:956-62

64 Maksymowych WP, Lambert R, Jhangri GS, Leclercq S, Chiu P, Wong $B$, et al. Clinical and radiological amelioration of refractory peripheral spondyloarthritis by pulse intravenous pamidronate therapy. J Rheumatol 2001;28:144-55.

65 Maksymowych WP, Jhangri GS, Fitzgerald AA, LeClercq S, Chiu P, Yan $A$, et al. A six-month randomized, controlled, double-blind, dose-response comparison of intravenous pamidronate $(60 \mathrm{mg}$ versus $10 \mathrm{mg}$ ) in the treatment of nonsteroidal anti-inflammatory drug-refractory ankylosing spondylitis. Arthritis Rheum 2002;46:766-73.

66 Adami S, Zamberlan N. Adverse effects of bisphosphonates. Drug Saf 1996; 14:158-70.

67 Dagfinrud H, Hagen K. Physiotherapy interventions for ankylosing spondylitis (Cochrane review). Cochrane Database Syst Rev 2001;4:CD002822

68 Hidding A, van der Linden S, Gielen X, de Witte L, Dijkmans B, Moolenburgh D. Continuation of group physical therapy is necessary in ankylosing spondylitis: results of a randomized controlled trial. Arthritis Care Res 1994:7:90-6.

69 Helliwell PS, Abbott CA, Chamberlain MA. A randomised trial of three different physiotherapy regimens in ankylosing spondylitis. Physiotherapy 1996;82:85-90.

70 Kraag G, Stokes B, Groh J, Helewa A, Goldsmith C. The effects of comprehensive home physiotherapy and supervision on patients with ankylosing spondylitis: a randomized controlled trial. J Rheumatol 1990; 17:228-33

71 van Tubergen A, Landewe R, van der Heijde D, Hidding A, Wolter N, Asscher $M$, et al. Combined spa-therapy is effective in patients with ankylosing spondylitis: a randomized controlled trial. Arthritis Rheum 2001;45:430-8 
72 van Tubergen A, Boonen, A, Landewé $R$, Rutten-van Mölken $M$, van der Heijde D, Hidding A, et al. Cost-effectiveness of combined spa-exercise therapy in ankylosing spondylitis: a randomized controlled trial. Arthritis Rheum (in press).

73 Fox MW, Onofrio BM, Kilgore JE. Neurological complications of ankylosing spondylitis. J Neurosurg 1993;78:871-8.

74 Ramos-Remus C, Gomez-Vargas A, Hernandez-Chavez A, Gamez-Nava JI, Bnozalez-Lopez L, Russell AS. Two year follow-up of anterior and vertical atlantoaxial subluxation in ankylosing spondylitis. J

75 Vheumatol 1997; $24: 507-10$. thoracolumbar kyphotic deformity in ankylosing spondylitis. A structured review of three methods of treatment. Ann Rheum Dis 1999;58:399406

76 Sweeney S, Gupta R, Taylor G, Calin A. Total hip arthroplasty in ankylosing spondylitis: outcome in 340 patients. J Rheumatol 2001;28:1862-6. 